\title{
c-Raf Regulates Cell Survival and Retinal Ganglion Cell Morphogenesis during Neurogenesis
}

\author{
Belén Pimentel, ${ }^{1}$ Carmen Sanz, ${ }^{2}$ Isabel Varela-Nieto, ${ }^{2}$ Ulf R. Rapp, ${ }^{3}$ Flora De Pablo, ${ }^{1}$ and \\ Enrique J. de la Rosa ${ }^{1}$
}

1Department of Cell and Developmental Biology, Centro de Investigaciones Biológicas, Consejo Superior de Investigaciones Científicas (CSIC), E-28006 Madrid, Spain, 2/nstituto de Investigaciones Biomédicas Alberto Sols, CSIC-Universidad Autónoma de Madrid, E-28029 Madrid, Spain, and 3/nstitut für medizinische Strahlenkunde und Zellforschung, University of Würzburg, D-97078 Germany

The signaling cascade Ras/Raf/mitogen-activated protein kinases modulates cell proliferation, differentiation, and survival, all key cellular processes during neural development. To better define the in vivo role of Raf during chick retinal neurogenesis, we interfered with Raf-dependent signaling during days 4.5 to 7.5 of embryonic development by expressing a dominant negative mutant of c-Raf ( $\Delta$ Raf), which blocks Ras-dependent Raf activation, and by overexpressing wild-type c-Raf. $\Delta$ Raf expression induced an increase in cell death by apoptosis, whereas it did not affect overall cell proliferation and differentiation. In parallel, the number of Islet-1/2-positive and TUJ1- positive retinal ganglion cells were diminished in their definitive layer, whereas there was an increase in the number of mislocated Islet-1/2-positive cells. This disturbed morphogenesis correlated with a disruption of the optic fiber layer. Conversely, c-Raf overexpression caused moderate opposite effects on apoptosis. These results frame in vivo early neurogenesis processes in which c-Raf is essential.

Key words: apoptosis; cell death; cell survival; neural development; neurogenesis; retinal ganglion cell; signaling; chick embryo
The cellular complexity of the nervous system is generated primarily during neurogenesis. In the chick retina, a well characterized vertebrate model system, neurogenesis begins with the birth of the ganglion cells and follows gradients of sequential, but overlapping, differentiation of all neural cell types (Prada et al., 1991). Retroviral or molecular lineage-tracing results in several vertebrate retinas suggest that evolving environmental signals, acting on progressively fate-restricted, heterogeneous subpopulations of neural precursor cells, underlie the regulation of neurogenesis (Turner and Cepko, 1987; Holt et al., 1988; Wetts and Fraser, 1988; Turner et al., 1990; Altshuler et al., 1991; Fekete et al., 1994; Hernández-Sánchez et al., 1994; Cepko et al., 1996; Alexiades and Cepko, 1997; Harris, 1997; Cameron et al., 1998; Lillien, 1998; Reh and Levine, 1998). Multiple growth factors regulating neurogenesis in vertebrates have been identified (for review, see Harris, 1997; Cameron et al., 1998). Their precise functions remain obscure, however, in large part because of the fact that their signaling pathways, including often the Ras/Raf/ mitogen-activated protein (MAP) kinases signaling cascade, have

\footnotetext{
Received Sept. 7, 1999; revised Dec. 23, 1999; accepted Feb. 15, 2000.

This study was supported by Dirección General de Investigación y Desarrollo (Spain) Grants P.M.96-0003 (to E.J.d.I.R.), PB97-0143 (to F.d.P.), and P.M.960075 to (I.V.-N.). The fellowships to B.P. and C.S. were awarded by the Ministerio de Educación y Cultura (Spain). We thank S. C. McLoon for the gift of RA4, R. Adler, J. Pérez-Miguelsanz, and C. Prada for critical reading of this manuscript, and V. Quesada for technical assistance. The 39.4D5 hybridoma and G3G4 and AMV3C2 monoclonal antibodies, generated by T. M. Jessell, S. J. Kaufman, and D. Boettiger, respectively, were obtained from the Developmental Studies Hybridoma Bank developed under the auspices of the National Institute of Child Health and Human Development and maintained by The University of Iowa, Department of Biological Sciences (Iowa City, IA).

Correspondence should be addressed to Enrique J. de la Rosa, Centro de Investigaciones Biológicas, CSIC, Velázquez 144, E-28006 Madrid, Spain. E-mail: ejdelarosa@cib.csic.es.

Copyright (C) 2000 Society for Neuroscience $\quad 0270-6474 / 00 / 203254-09 \$ 15.00 / 0$
}

been mostly characterized in transfected cell lines. Under such conditions, they show much less specificity and selectivity than thought to be required for fine-tuned regulation of developmental processes (Chao, 1992). In vivo analysis of the signaling molecules should reveal those processes for which a molecule is essential. This rationale, underlying transgenic and knock-out mouse models, is feasible in the chick embryo through the use of retroviral gene-transfer techniques (Morgan et al., 1992; Cepko et al., 1998).

The protein kinase Ras/Raf/MAP kinases signaling cascade is a central pathway in the transmission of growth factor stimuli (Daum et al., 1994; Magnuson et al., 1994; Marshall, 1994; De Pablo and de la Rosa, 1995; Ferrell, 1996; Rommel and Hafen, 1998). The Raf family of Ser/Thr kinases is involved in the regulation of developmental processes, as shown by genetic analysis in various organisms (Dickson et al., 1992; Han et al., 1993; Pritchard et al., 1996; Wojnowski et al., 1997, 1998). In chicken, there are homologs of c-Raf, termed c-mil (Jansen and Bister, 1985), and B-Raf, termed c-Rmil (Calogeraki et al., 1993), both found in the embryonic retina (Marx et al., 1988a,b; Calogeraki et al., 1993). Although the knock-out approach in mouse has confirmed essential functions in development for Raf, no detailed information is available on phenotypes affecting the nervous system. The retroviral gene-transfer approach has demonstrated recently that, in the chick embryo, normal otic organogenesis requires strict maintenance of c-Raf levels (Sanz et al., 1999).

We show here that c-Raf is expressed in early retinal development. Interference with endogenous Raf expression by means of retroviral gene transfer, including either c-Raf overexpression or the expression of a dominant negative form ( $\Delta \mathrm{Raf})$, affected cell survival and the morphogenesis of retinal ganglion cells. We can 

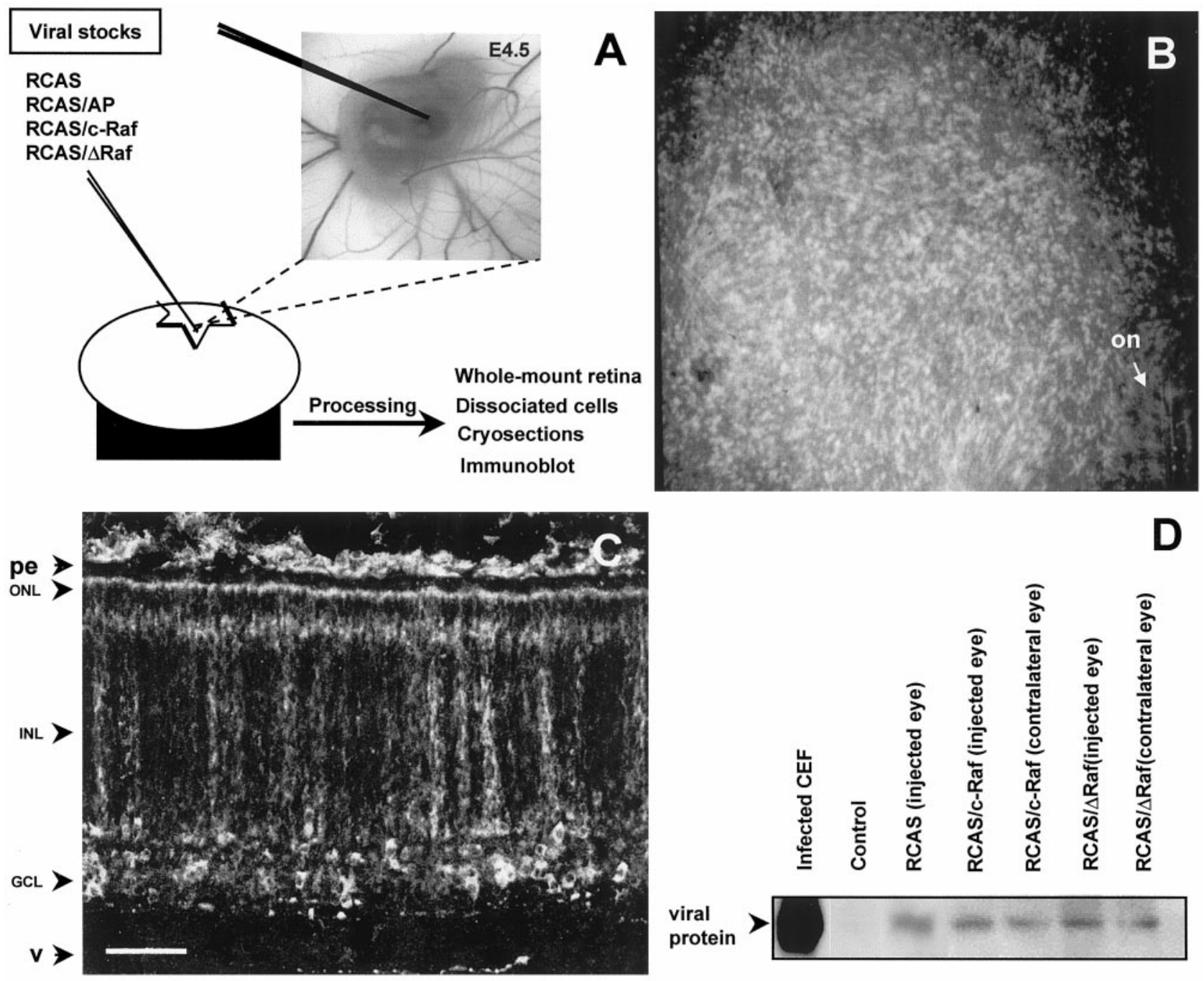

Figure 1. Retroviral infection of chick embryonic retina. $A$, Schematic representation of the viral injection at E4.5, as described in Materials and Methods. Viral infection was monitored by immunostaining with the monoclonal antibody anti-Gag19, as shown in $B-D$. $B$, A low-magnification micrograph of a whole-mount stained infected retina. $C$, A stained retinal cryosection shows the widespread, clonal-reminiscent distribution of the infected cells. The retinal layers are indicated: on, optic nerve head; $p e$, pigmented epithelium; $O N L$, outer nuclear layer; $I N L$, inner nuclear layer; $G C L$, ganglion cell layer; $v$, vitreous humor. $D$, A representative immunoblot of infected neuroretinas. Compare the expression levels between the injected and the contralateral eye of the same embryo. Infected chick embryonic fibroblasts $(C E F)$ and the retina of a noninjected embryo $(C o n t r o l)$ are shown. Scale bar: $B, 1 \mathrm{~mm} ; C, 50 \mu \mathrm{m}$.

therefore conclude that c-Raf is essential for defined processes during retinal neurogenesis in vivo.

\section{MATERIALS AND METHODS}

Construction of viral vectors and production of viral stocks. RCAS envelope subgroup A, a replication-competent retroviral vector derived from Rous sarcoma virus, was a generous gift of Dr. S. Hughes (National Cancer Institute, Frederick, MD) (Hughes et al., 1987). The cDNAs of c-Raf (Heidecker et al., 1990), Raf-C4, a dominant negative Raf construct (Bruder et al., 1992; Owaki et al., 1993), and alkaline phosphatase, as a control gene, were cloned into RCAS as described previously (Sanz et al., 1999). Chick embryonic fibroblasts, obtained from specific pathogen-free fertilized eggs, were transfected with either the empty vector plasmid (referred to here as RCAS) or those containing the c-Raf (RCAS/c-Raf), the Raf-C4 (RCAS/ $\mathrm{Raf}$ ), or the alkaline phosphatase (RCAS/AP) inserts. The viral supernatants of infected cultures were collected and concentrated 100 -fold by ultracentrifugation, as described previously (Sanz et al., 1999). Concentrated stocks were aliquoted and kept frozen at $-80^{\circ} \mathrm{C}$. Typical titers determined in the concentrated stocks before freezing were in the range $2-3 \times 10^{8} \mathrm{pfu} / \mathrm{ml}$.

Viral infection of embryonic retina. Chicken embryos at the indicated ages were obtained by incubation of fertilized White Leghorn eggs (Granja Rodríguez-Serrano, Alba de Tormes, Spain.) at $38.4^{\circ} \mathrm{C}$. Retinas were infected at embryonic day 4.5 (E4.5), as depicted in Figure $1 A$. Through a lateral window in the shell, $1 \mu \mathrm{l}$ of viral stock was injected into the vitreous humor with a glass capillary. The window was sealed with cello tape, and the egg was further incubated for the indicated periods. It is worth noting that effective RCAS integration requires a pass through an S-phase. Therefore, phenotypic analysis includes only those cells actively proliferating at the moment of the infection. Concentrated viral stocks produced high embryo lethality, even those corresponding to the empty vector (RCAS) or the control gene (RCAS/AP). This death was probably caused by massive viral infection, because mortality decreased in parallel to viral dilution. Viral stocks were therefore used at the highest concentration, producing $<50 \%$ embryonic lethality. The resulting viral dose per injected embryo was in the range $2.5-10 \times 10^{4} \mathrm{pfu}$. Three different viral stocks of each construct were used in at least four independent experiments. A total of 176 embryos injected with the control viruses (RCAS or RCAS/AP), 208 embryos injected with RCAS/ $\Delta \mathrm{Raf}$, and 180 embryos injected with RCAS/c-Raf were analyzed by different techniques (Fig. $1 A$ and see below). Retroviral infection of E4.5 retinas provoked a widespread infection $48-72 \mathrm{hr}$ later, which could be 
visualized by either immunohistochemistry (Fig. $1 B, C$ ) or immunoblotting (Fig. $1 D$ ) for the viral protein Gag19. Unexpectedly, but correlating with a widespread infection as stated previously, infected cells were found outside the injected retina, including the head mesenquima, the cephalic vesicles, and the contralateral eye. We took advantage of this fact for normalization purpose. The infection levels were routinely estimated in the contralateral eye to select embryos injected with the different constructs with similar levels of viral infection for further study (Fig. 1D). In addition, Gag19 was also determined in selected samples of all the analyzed embryos.

Immunostaining. Whole-mount retina, retinal cryosections, and dissociated cells were prepared and stained basically as described previously (de la Rosa et al., 1990, 1998). Before staining, whole-mount retinas were permeated with $1 \%$ (w/v) Triton X-100 (Fluka, Buchs, Switzerland) and treated with $20 \mathrm{U} / \mathrm{ml}$ collagenase type V I (Sigma, St. Louis, MO) for 15 min at $37^{\circ} \mathrm{C}$. Similarly, retinal sections and dissociated cells were microwaved in $10 \mathrm{~mm}$ citrate, $\mathrm{pH} 6.0$, for $10 \mathrm{~min}$ and permeated with $0.1 \%$ $(\mathrm{w} / \mathrm{v})$ Triton X-100. Effects on retinal ganglion cells were assessed by staining with monoclonal antibodies (mAb) against G4/Ng-CAM (1:1000 from ascitic fluid) (de la Rosa et al., 1990), Islet-1/2 (1:200 from ascitic fluid; clone 39.4D5 from the Developmental Studies Hybridoma Bank, University of Iowa, Iowa City, IA) (Austin et al., 1995), RA4 (1:10 from hybridoma culture supernatant; kindly provided by Dr. Steve C. McLoon, University of Minnesota, Minneapolis, MN) (McLoon and Barnes, 1989), and TUJ1 (1:1000; Medpass, Luxembourg) (Snow and Robson, 1995). In selected cases, viral infection was revealed by either simultaneous or parallel staining with a anti-Gag19 monoclonal antibody (1:500 dilution from concentrated immunoglobulins; clone AMV-3C2 from the Developmental Studies Hybridoma Bank). Staining was developed by consecutive incubations with biotin-conjugated goat anti-mouse Ig (1:200) and Cy2-streptavidin (1:200) or directly by incubation with Cy3-antimouse Ig (1:200; all from Amersham Pharmacia Biotech, Rainham, Essex, UK). Incubation and washing steps were as described previously (de la Rosa et al., 1998). Immunofluorescence was visualized using a Zeiss (Oberkochen, Germany) Axioscop, a Zeiss Axioplan equipped with a cooled CCD camera (CH250/A; Photometrics, Tucson, AZ), or a laser scanning confocal microscope (MRC 1024; Bio-Rad, Richmond, CA). Images were digitalized and mounted in Adobe Photoshop 4.0 (Adobe Systems, San Jose, CA).

Immunoblotting. Analysis of the contralateral retina by immunoblotting was demonstrated to be a rapid and effective method to assess viral infection, and it preserved the injected retina for alternative processing other than immunoblot. Briefly, retinas were solubilized in SDS-PAGE sample buffer, fractionated by SDS-PAGE, and transferred to nitrocellulose membranes using standard methods (Hernández-Sánchez et al., 1994). Blots were stained with Ponceau S (Sigma) to verify equal protein loading in all lanes. Blots were stained with monoclonal antibody antiGag19 (1:5000 dilution) and developed with peroxidase anti-mouse Ig (1:30000; Jackson ImmunoResearch, West Grove, PA) using the ECL system (Amersham Pharmacia Biotech). Gag19 was also determined in the extracts of infected retinas. Endogenous c-Raf was determined in noninfected embryos. Virally transfected c-Raf and $\Delta$ Raf were determined directly in the injected retina. For these determinations, retinas were homogenized in radioimmunoprecipitation buffer [ $10 \mathrm{~mm}$ Tris$\mathrm{HCl}, \mathrm{pH} 8.0,150 \mathrm{~mm} \mathrm{NaCl}, 1 \%$ (w/v) Triton X-100, and protease inhibitor cocktail (Boehringer Mannheim, Mannheim, Germany)]. Protein concentration was estimated by the BCA protein assay (Pierce, Rockford, IL), and equal amounts were loaded. Blots were stained with either rabbit polyclonal antiserum against human c-Raf (1:500; Upstate Biotechnology, Lake Placid, NY), which recognizes specifically chick c-Raf (Sanz et al., 1999), or with rabbit polyclonal antiserum against 17 amino acids of B-Raf included in the Raf-C4 construct (1:100) (Bruder et al., 1992; Owaki et al., 1993), and peroxidase anti-rabbit Ig (1:10000; Jackson ImmunoResearch). All the blots were restained with mouse $\mathrm{mAb}$ anti- $\alpha$-tubulin (1/5000; Sigma) and peroxidase anti-mouse Ig (1: 30000; Jackson ImmunoResearch) to allow for relative quantitation by densitometry. For phosphorylated MAP kinase and Akt determinations, the injected retinas were prepared in the same way, but in the presence of $2 \mathrm{~mm} \mathrm{Na}$ orthovanadate, $4 \mathrm{~mm} \mathrm{Na}$ pyrophosphate, and $0.1 \mathrm{M} \mathrm{NaF}$, as phosphatase inhibitors. The specific primary antibodies were as follows: $\mathrm{mAb}$ anti-MAP kinase (1:3000; Zymed, San Francisco, CA), goat polyclonal antibodies anti-Akt1(1:1000; Santa Cruz Biotechnology, Santa Cruz, CA), rabbit polyclonal antibodies anti-phospho-Akt (1:1000; New England Biolabs, Beverly, MA), and rabbit polyclonal antibodies antiphospho-MAP kinase (1:700; New England Biolabs). Blots were devel- oped as above with the corresponding peroxidase-conjugated secondary antibodies.

Identification of apoptotic cells. The terminal deoxynucleotidyl transferase-mediated biotinylated UTP nick end labeling (TUNEL) protocol to visualize fragmented DNA in apoptotic cells, modified from Blaschke et al. (1996), was performed on whole-mount retina and retinal sections essentially as described previously (Díaz et al., 1999), with two modifications. The incubation in proteinase $\mathrm{K}$ was replaced by an incubation in collagenase to preserve protein epitopes for double staining, and the reaction was terminated by a $2 \mathrm{hr}$ incubation in $300 \mathrm{~mm} \mathrm{NaCl}$ and $30 \mathrm{~mm}$ sodium citrate, $\mathrm{pH}$ 6.0. The TUNEL signal was visualized with Cy2-streptavidin (1:200 dilution; Amersham Pharmacia Biotech). Pyknotic bodies were counted either directly under the microscope or using the OPTIMAS program (OPTIMAS Corporation, Bothell, WA) on digital images, and the results were represented as isothanas (isodensity curves of dead cells) as described previously (Díaz et al., 1999). For double staining, incubations with the primary antibody were performed before the TUNEL reaction. Preparations were visualized as above. Occasionally, apoptotic cells with pyknotic nuclei were counted in retinal sections and dissociated retinal cell preparations after 4',6-diamidino-2phenylindole (Sigma) staining.

Identification of proliferating cells. Actively proliferating neuroepithelial cells were labeled with methyl- $\left[{ }^{3} \mathrm{H}\right]$ thymidine and bromodeoxyuridine (BrdU). Embryos injected with the viral stocks at E4.5 were labeled with $25 \mu \mathrm{Ci}$ of methyl $\left[{ }^{3} \mathrm{H}\right]$ thymidine $(85 \mathrm{Ci} / \mathrm{mmol}$; Amersham Pharmacia Biotech) $36 \mathrm{hr}$ after injection and with $25 \mu \mathrm{g}$ of BrdU (Sigma) $47 \mathrm{hr}$ after injection. Embryos were killed $48 \mathrm{hr}$ after injection, and the retinas were processed to obtain a single-cell suspension, as described previously (de la Rosa et al., 1998). Aliquots of 50,000 cells were subjected to cytospin on glass slides and stained with anti-BrdU antibody (1:2000 dilution from concentrated immunoglobulins; clone G3G4 from Developmental Studies Hybridoma Bank), biotin-conjugated goat anti-mouse Ig (1:200), and Cy2-streptavidin (1:200) as above. Afterwards, the samples were dehydrated for autoradiography with NTB2 nuclear emulsion (Eastman Kodak, Rochester, NY), as described previously (de la Rosa et al., 1998). After $10 \mathrm{~d}$ of exposure and development of the emulsion, the samples were counterstained with 4',6-diamidino-2-phenylindole and mounted.

\section{RESULTS}

\section{C-Raf is expressed in early retinal neurogenesis}

Before the manipulation of Raf during retinal neurogenesis, we analyzed its endogenous levels by immunoblot (Fig. $2 A$ ). c-Raf was detected during the entire period studied in this work, with the highest levels at E4.5 and E7.5. This regulated endogenous expression of c-Raf supports the physiological relevance of its manipulation by retroviral gene transfer. The observed regulation of c-Raf levels in the neuroretina correlates neither with global cell proliferation, which decreases progressively as development proceeds, nor with global cell differentiation, which increases progressively during the same period (Prada et al., 1991). The intravitreal retrovirus injection at $\mathrm{E} 4.5$ caused a widespread retinal infection. Clonal-reminiscent infected patches of cells were distributed all over the retina, with no biased regional differences, intermixed with other patches of Gag19-negative cells (Fig. $1 B, C)$. At the level of the ganglion cells, $\sim 10-30 \%$ of the cells were positive for Gag19. The viral infection modified the detectable c-Raf (Fig. 2B). RCAS/c-Raf increased the total retinal c-Raf in the range of 1.5- to 3-fold with respect to RCAS, the virus without insert. RCAS/ $\mathrm{Raf}$ produced a nonsignificant, slight decrease in endogenous c-Raf, whereas the mutant form was detected as expected, only in the RCAS/ $\Delta$ Raf-infected retinas. $\Delta$ Raf expression altered the downstream signaling pathway. In massively infected fibroblasts, IGF-I-induced phosphorylation of MAP kinase was almost completely inhibited (Sanz et al., 1999). In the present work, neuroretina was infected to a lesser extent and maintained in ovo in the presence of all the natural stimuli. Consequently, the modifications were of lower magnitude but reproducible in their tendency. Compared with the RCAS/c- 

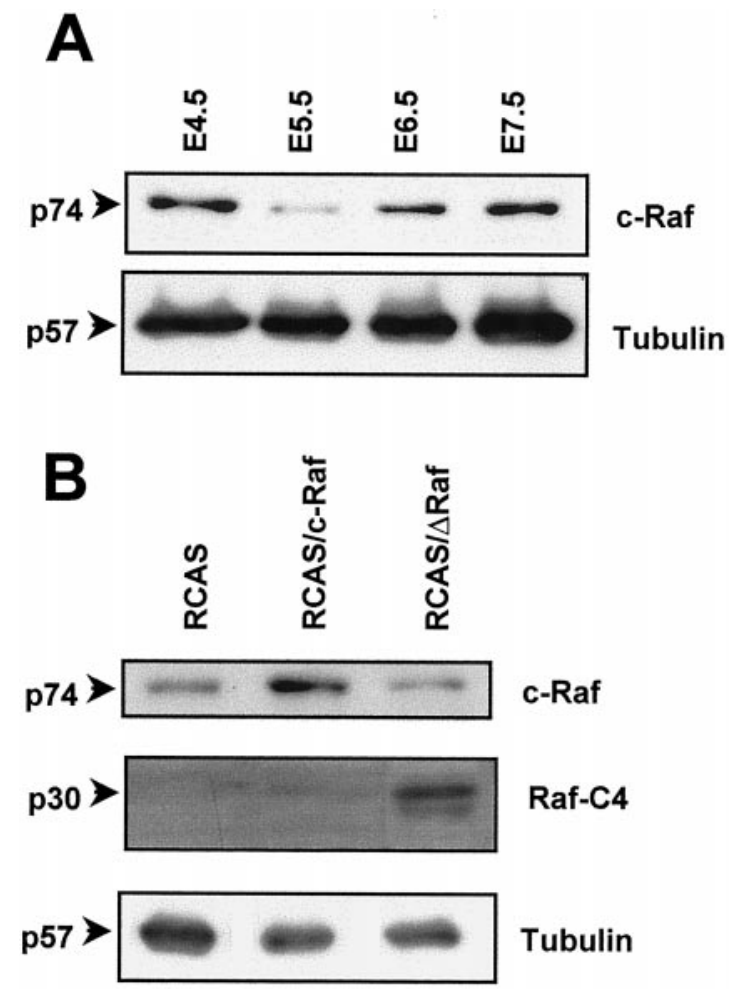

Figure 2. Endogenous expression of c-Raf and interference by viral infection. $A$, A representative immunoblot of retinal extracts of the indicated embryonic days revealing the endogenous c-Raf expression in the retina. $B$, A representative immunoblot showing c-Raf expression 48 $\mathrm{hr}$ after injection of virus, as well as Raf-C4 expression $72 \mathrm{hr}$ after injection of virus. Note that both the endogenous expressed chick c-Raf and the virally transferred human c-Raf are recognized by the antibody used and comigrate in the gel. All the blots were restained for tubulin to allow for relative quantitation.

Raf-infected retinas, $\Delta$ Raf expression decreased the relative level of phosphorylated MAP kinase to $0.58-0.75$ and the level of phosphorylated Akt to 0.83-0.88.

\section{Dominant negative Raf expression induces apoptosis}

Among the cell processes in which c-Raf could be involved, a prominent effect was found only on cell survival. $\Delta$ Raf expression provoked an increase in apoptosis. A larger number of TUNELpositive, apoptotic cells was found in the RCAS/ $\Delta$ Raf-infected retinas (Figs. 3, 4C,F) than in the retinas infected with RCAS, RCAS/c-Raf (Figs. 3, 4), or RCAS/AP (data not shown). This effect was prevalent $48 \mathrm{hr}$ after viral injection and decreased at longer times. On the contrary, $\Delta$ Raf expression did not significantly alter the total proportion of proliferating neuroepithelial cells, as determined by thymidine and BrdU incorporation (Fig. 3 ). Whereas preexisting neurons do not integrate retrovirus, all proliferating cells are, in principle, susceptible to retroviral genome integration. In addition, $\Delta$ Raf expression did not reduce the overall proportion of differentiated ganglion cell neurons 48 hr or $72 \mathrm{hr}$ after viral injection (Figs. 3, $5 A$ ), as determined by Islet- $1 / 2$ staining of dissociated retinal cells.

To better characterize the observed effect of $\Delta$ Raf expression in induction of cell death, the apoptotic cell distribution was determined by TUNEL in whole-mount retinas and represented as isothanas (Fig. 4A-C). Also by this representation, an overall increase in apoptosis was clearly observable in the RCAS/ $\Delta$ Rafinfected retinas, whereas overexpression of c-Raf decreased mod-

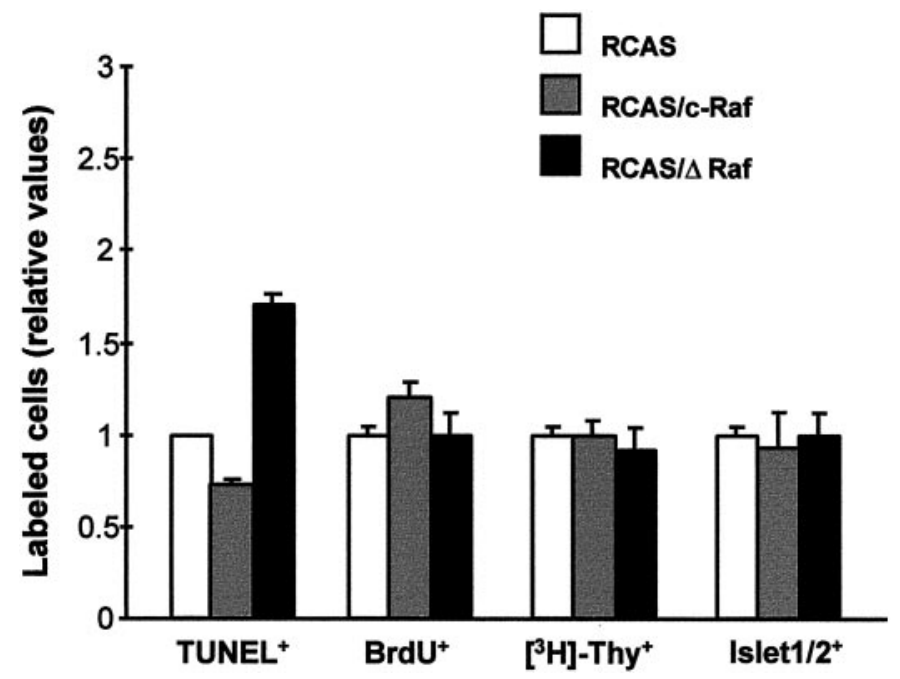

Figure 3. Interference with Raf affects prominently cell survival, but not proliferation and differentiation. Retinas infected with the indicated viral constructs were processed $48 \mathrm{hr}$ after injection. Apoptosis was visualized by TUNEL in whole-mount retina and scored directly under the microscope or using the Optimas program (3 retinas). The individual values obtained by the different techniques were relativized to those of the RCAS-infected retinas and combined. Proliferation was quantitated by BrdU immunostaining after $1 \mathrm{hr}$ incorporation or by $\left[{ }^{3} \mathrm{H}\right]$-thymidine autoradiography after $12 \mathrm{hr}$ incorporation in dissociated cells. Differentiation was determined by Islet-1/2 immunostaining in dissociated cells. In all the determinations in dissociated cells, 500 total cells were counted in duplicates of three infected embryos per viral construct.

estly the number of apoptotic cells (Figs. 3, 4A-F). The highest density was localized, in all cases, around the optic fissure and dorsal of the optic nerve head, a pattern reminiscent of the naturally occurring death (Díaz et al., 1999). In an attempt to identify the dying cells, a double staining was performed combining TUNEL with immunostaining with several markers for neurons and ganglion cells, the major neuronal cell type generating at the studied ages. These included Islet-1/2, RA4, and TUJ1. TUNEL-positive cells were not stained by any one of the markers (Fig. 4G-I, and data not shown). In contrast, most of the dead cells observed in RCAS-, RCAS/c-Raf-, or RCAS/DRafinfected retinas, identified in this case by their pyknotic nuclei, were labeled with thymidine (up to $75 \%$ of total apoptotic cells), indicating that dying cells had gone through an S-phase in the last $12 \mathrm{hr}$. A similar situation is found naturally in ovo, despite the differences in the level of apoptosis (Díaz et al., 1999; data not shown). Together, these data suggest that a critical period of regulation of cell survival exists a short time after an S-phase, during which c-Raf signaling is essential.

\section{Retinal ganglion cell morfogenesis is disrupted by dominant negative Raf expression}

$\Delta$ Raf expression altered the morphogenesis of the retinal ganglion cells, which is the main differentiation process occurring at E4.5. This effect was first observed in double-stained infected retinas by TUNEL and Islet-1/2 immunostaining. It is worth noting that, at the studied ages, Islet- $1 / 2$ resulted in being a highly selective, even specific, marker of retinal ganglion cells in the control embryos (Fig. 4G, and data not shown of noninfected embryos). Although no colocalization of both labels was observed, the thickness of the Islet-1/2-positive ganglion cell layer of $\mathrm{RCAS} / \Delta$ Raf-infected retinas was clearly reduced in the areas of high density of apoptosis (Fig. 4G,I). Interestingly, in the same 


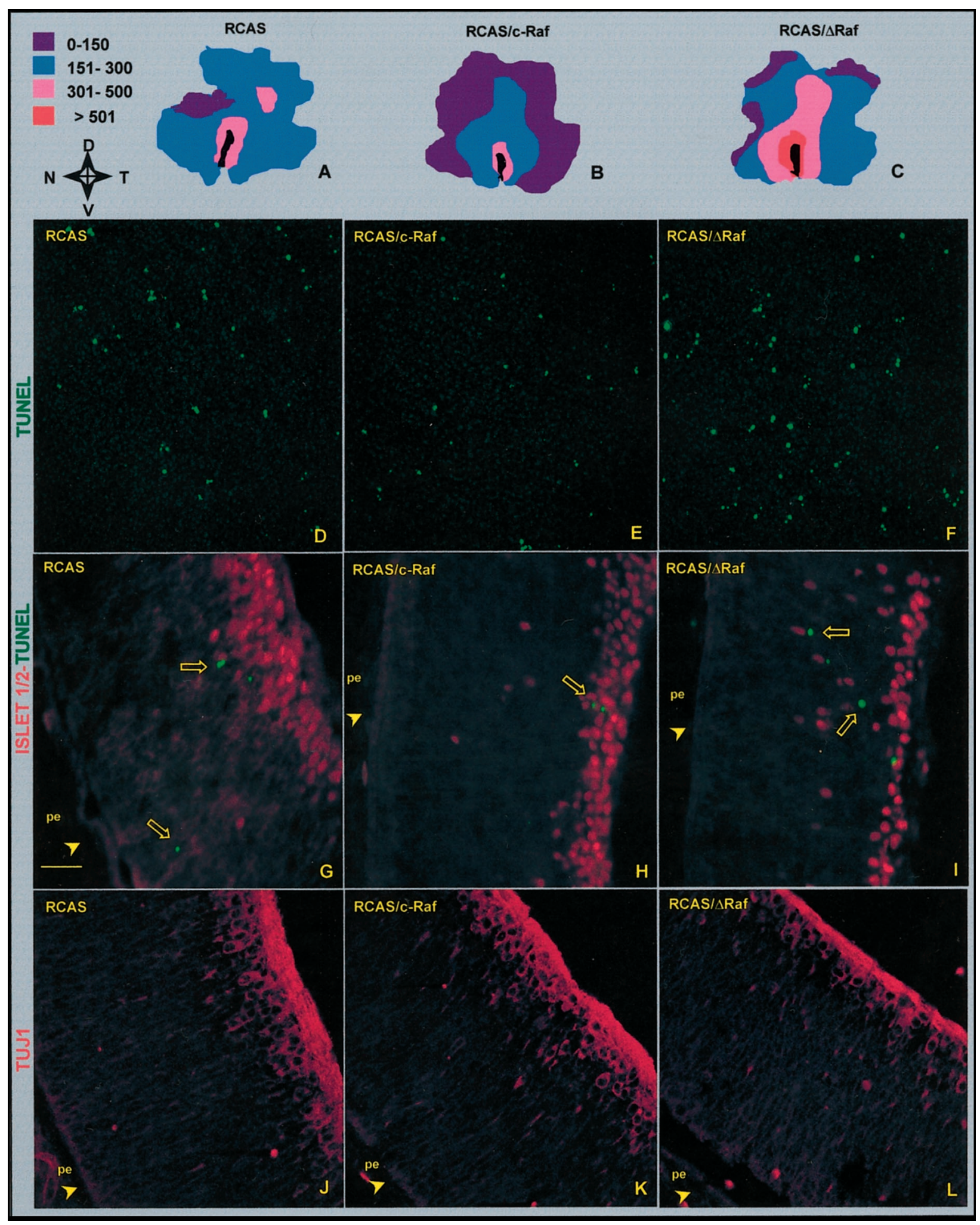

Figure 4. Effect of the interference with Raf on apoptosis and the morphogenesis of the ganglion cells. Retinas injected at E4.5 with the indicated viral constructs were processed for TUNEL in whole-mount retina $(A-F)$ or for immunostaining in retinal cryosection $(G-L) 48 \mathrm{hr}$ after injection. Retinas with total dead cell scores closest to the average value (see Fig. 3 ) were represented as isothanas $(A-C$; the pseudocolor scale indicates dead cell density per square millimeter). The orientation of the retinas is indicated: $N$, nasal; $T$, temporal; $D$, dorsal; $V$, ventral. Comparative fields in the temporoventral quadrant were obtained by confocal microscopy of the represented retinas $(D-F)$. Double-stained cryosections for the neuronal cell marker Islet-1/2 (red) and apoptotic cells by TUNEL ( green) $(G-I)$. Note that, in the control infection with empty vector $(G)$, at this age, Islet-1/2 is a selective nuclear marker of ganglion cells located in their proper layer. Serial sections stained for the ganglion cell marker TUJ1, which also stains the optic fiber layer ( $J-L)$. In all cases, only sections including the lens and the optic nerve were chosen, and temporal fields $0.5 \mathrm{~mm}$ away from the optic nerve head are shown. The pigmented epithelium ( $p e$ ) side is indicated. Scale bar: $A-C, 1.5 \mathrm{~mm} ; D-F, 40 \mu \mathrm{m} ; G-L, 20 \mu \mathrm{m}$. 


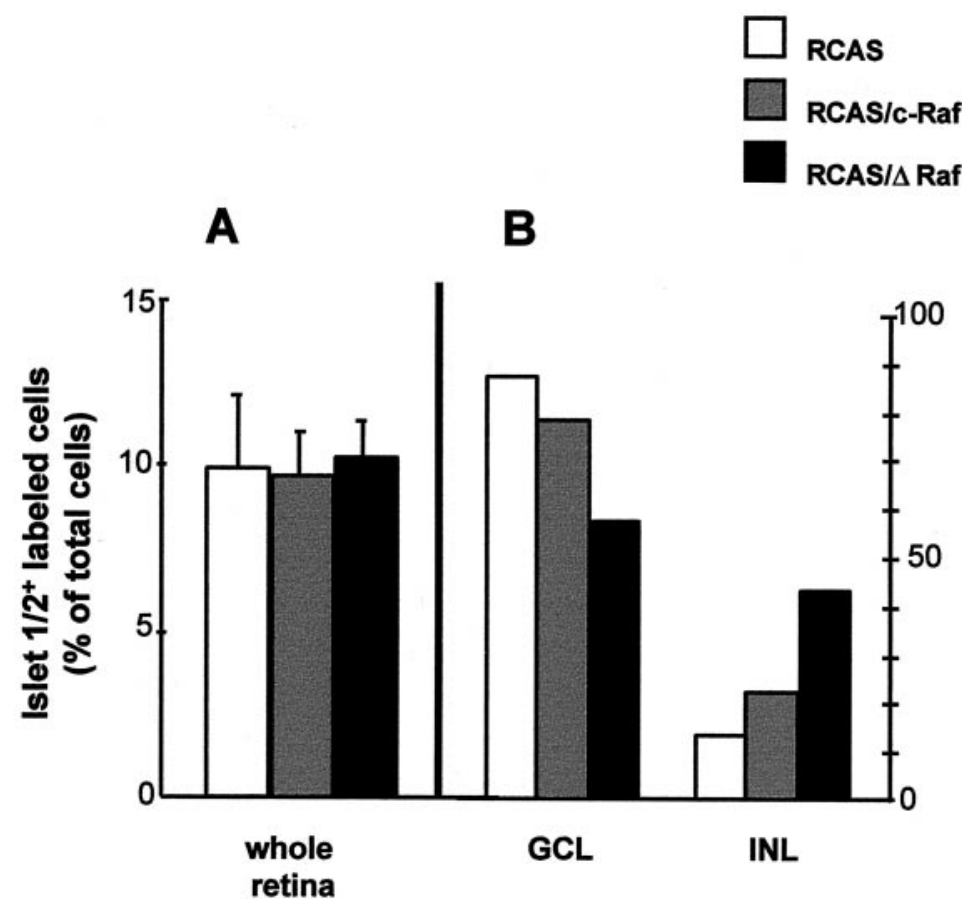

region, mislocated Islet-1/2-positive cells were found (Figs. 4I, $5 B)$. Overall, the total number of Islet-1/2-positive cells within the whole retina did not differ significantly among different infections (Fig. $5 A$ ), but their distribution throughout the retinal layers was clearly altered. In the most affected regions, the RCAS $/ \Delta$ Rafinfected retinas showed a relative reduction of $35 \%$ in Islet-1/2positive cells in the ganglion cell layer and the corresponding fourfold increase in the prospective inner nuclear layer (Fig. 5B). The reduction of the ganglion cell layer in the RCAS/ $\mathrm{Raf}$ infected retinas was also clearly revealed by TUJ1 staining (Fig. $4 J-L)$, although with this marker, as well as with RA4 staining (data not shown), no mislocated cells were as evident as those stained by Islet-1/2 (Fig. 4I). No apparent effects of c-Raf overexpression were observed at the level of the retinal ganglion cell layer (Fig. 4H,K).

The selective disruption of the retinal ganglion cell morphogenesis was confirmed in the optic fiber layer, formed by the ganglion cell axons, as visualized by G4/Ng-CAM staining (Fig. $6)$. This layer was well formed in RCAS- or RCAS/AP-infected retinas (Fig. 6A,B) and did not differ in appearance from an uninfected embryo (data not shown). $\Delta$ Raf expression severely disrupted this layer in defined regions, those of high density of apoptosis (Fig. 6C). This effect was already evident at $48 \mathrm{hr}$ after viral injection and increased by $72 \mathrm{hr}$, although the optic fiber layer recovered its normal morphology by $144 \mathrm{hr}$ after injection (data not shown).

\section{DISCUSSION}

The role of c-Raf during early neurogenesis has been analyzed here in vivo in the chick embryonic retina. Interference with the endogenously expressed c-Raf by retroviral gene transfer prominently affected cell survival and morphogenesis of the retinal ganglion cell and optic fiber layers. A dominant negative mutant $\Delta$ Raf increased apoptosis, which, remarkably, altered neither neuronal generation, as determined by Islet-1/2 expression, nor global retinal proliferation, as determined by DNA precursor incorporation. $\Delta$ Raf expression, however, reduced the number of
Islet-1/2-positive and TUJ1-positive cells located in the ganglion cell layer and severely disrupted the optic fiber layer. These findings demonstrate a quite selective function of the Ras/Raf/ MAP kinases cascade during early neurogenesis in vivo and broaden the physiological relevance of regulation of apoptosis in early neural development.

The in vivo approach of the present study has allowed the definition of an essential, specific effect of the pleiotropic signaling molecule c-Raf. Although it is clear that Raf is a central molecule in the transmission of growth factor stimuli (Daum et al., 1994; Magnuson et al., 1994; Marshall, 1994; Ferrell, 1996), the contradictory observations made in cell lines often obscure the specific, essential functions (Pritchard and McMahon, 1997). The knock-out approach in mouse has confirmed essential functions in development for Raf. c-Raf-, B-Raf-, and A-Raf-deficient mice are growth retarded, and embryonic lethality is high in those lacking c-Raf and B-Raf (Pritchard et al., 1996; Wojnowski et al., 1997, 1998). In addition, specific developmental defects have been reported for c-Raf and B-Raf (Wojnowski et al., 1997, 1998). In none of these studies an in depth analysis of the neural phenotype is reported. Our previous study of otic organogenesis using a similar retroviral approach (Sanz et al., 1999) has demonstrated that, in the chick embryo, normal otic organogenesis requires strict maintenance of c-Raf levels (Sanz et al., 1999). In this system, primarily epithelial at the developmental stage studied, overexpression of c-Raf increased proliferation and impaired differentiation in organotypic culture, whereas the expression of a c-Raf mutant that acts as a dominant negative form ( $\Delta \mathrm{Raf})$ had opposite effects. Cell death was not analyzed in detail, although apoptosis induced by NGF was prevented by c-Raf overexpression. In the present study, survival is the preferentially affected process by a subtle disruption of signaling through the Ras/Raf pathway, whereas proliferation and differentiation were altered little or not at all. This difference is likely to be attributable, at least in part, to the fact that the infected tissue in this study is highly proliferative as it is maintained in vivo. Under such condi- 


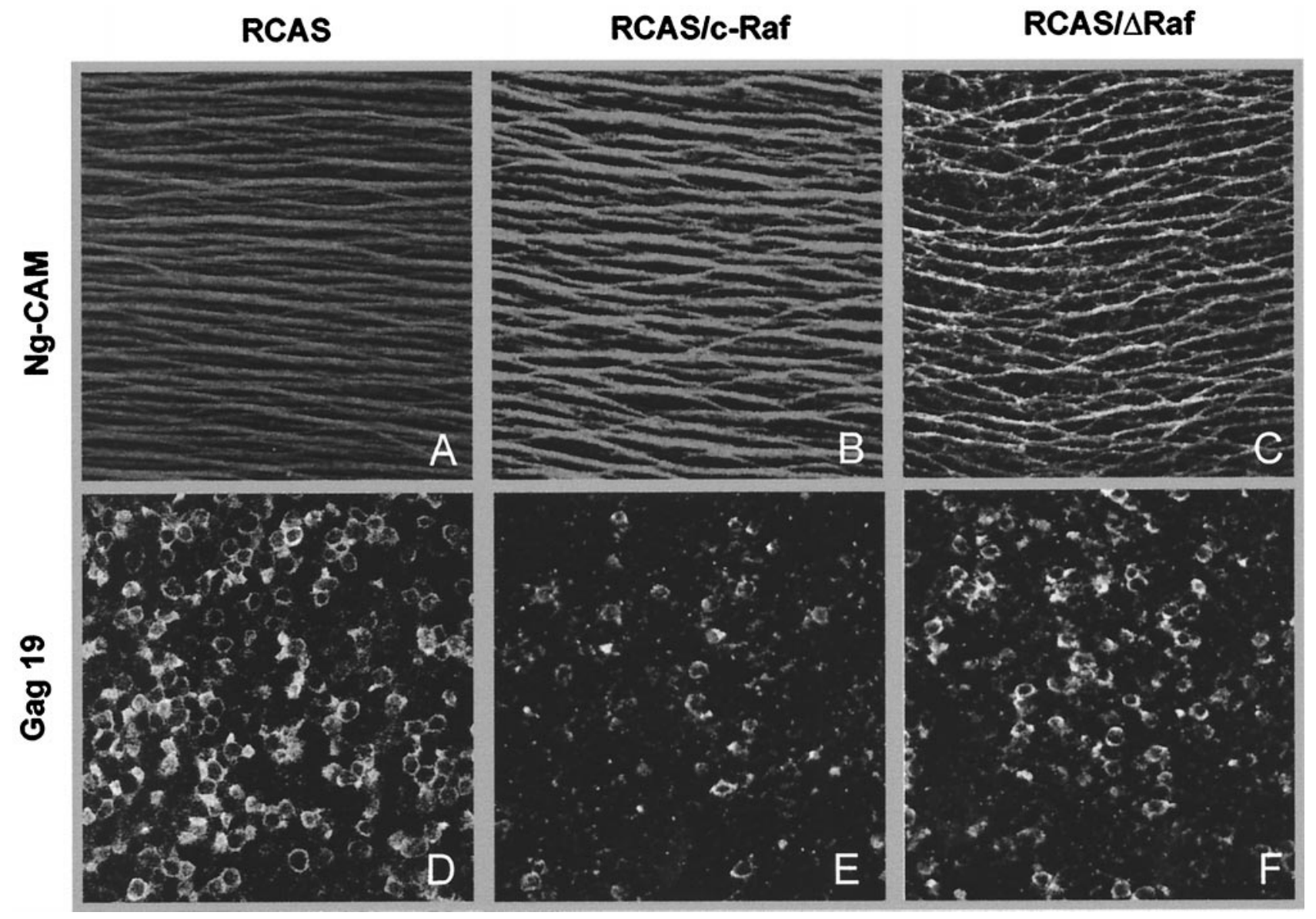

Figure 6. Phenotypic effect of the interference with Raf in the optic fiber layer. Retinas infected at E4.5 with RCAS ( $A, D)$, RCAS/C-Raf ( $B, E)$, or $\mathrm{RCAS} / \Delta \operatorname{Raf}(C, F)$ were processed $72 \mathrm{hr}$ after injection as whole mounts for double immunostaining of the axonal protein $\mathrm{G} 4 / \mathrm{Ng}-\mathrm{CAM}(A-C)$ and the viral protein Gag19 $(D-F)$. Optic sections were obtained every $0.5 \mu \mathrm{m}$, spreading the entire thickness of the optic fiber layer and combined to reconstruct the whole layer. In the same field, an optic section in the middle of the ganglion cell layer was obtained to assess the viral infection. Comparative fields in the temporoventral quadrant are shown for the different experimental cases.

tions, it is plausible that no further proliferation could be induced by wild-type c-Raf, whereas a decrease of proliferation in vivo may require a more dramatic inhibition of the MAP kinases pathway than that caused by $\Delta \mathrm{Raf}$ expression. Alternatively, strict regulation of cell survival-death may be more relevant in early neurogenesis than in otic organogenesis. We have reported previously the attenuation by insulin of apoptosis induced by growth factor deprivation in the neurulating embryo and the retina (Morales et al., 1997; Díaz et al., 1999, respectively). (Pro)insulin is endogenously expressed in the retina (Hernández-Sánchez et al., 1995) and triggers both the Ras/Raf/MAP kinases and the PI3 kinase/Akt pathways (for review, see De Pablo and de la Rosa, 1995; O’Brien and Granner, 1996). The observed effects of insulin in proliferation and differentiation, extensive to many other growth factors, may be, at least in part, late consequences of a primary effect in prevention of apoptosis. Concomitantly, the proliferative responses to Ras/Raf/MAP kinases pathway activation should be reinterpreted in the same way. Indeed, there may be an inverse linkage between apoptosis and proliferation, as a means of maintaining homeostatic balance in the size and architecture of tissues, organs, and organism.

The role and regulation of programmed cell death affecting connecting neurons is well characterized (Barde, 1989; Oppenheim, 1989, 1991), including that of chick retinal ganglion cells
(Rodríguez-Tébar et al., 1989; de la Rosa et al., 1994). Much less is known about the role of apoptosis in early neurogenesis, although it has been demonstrated in the early avian retina (Cuadros and Ríos, 1988; Martín-Partido et al., 1988; Frade et al., 1996; Frade et al., 1997; Cook et al., 1998). Recent studies during early neurogenesis have shown that most apoptotic cells were engaged in DNA synthesis shortly before death (Blaschke et al., 1998; Díaz et al., 1999). The cell death observed in the embryonic retina in vivo, however, does not affect all the neuroepithelial cells equally, but preferentially affects subpopulations in specific locations. Remarkably, when high apoptosis levels are induced by culture under growth factor deprivation conditions or by in ovo blockage of insulin signaling, the dead cells are distributed in a pattern coincident with that observed in vivo (Díaz et al., 1999, 2000). Similarly, in this study, the patterns of cell death after viral infection coincide for all the viral constructs used, despite differences in the number of dead cells. Together, these results suggest that the cells prone to die are involved in a defined cell process. In the time interval analyzed in detail, E4.5-E7.5, interference with signaling by $\Delta \mathrm{Raf}$ expression mainly affected the survival of cells engaged in an S-phase in the previous $12 \mathrm{hr}$ and the correct generation of the ganglion cell layer, which was clearly reduced. No colocalization of TUNEL with any of the tested 
ganglion cell markers was found or with the viral protein Gag19, probably because of the rapid onset of apoptosis and the activation of proteolitic cascades that degrade cytoskeletal and nuclear components (Prasad et al., 1999). However, very few TUNEL-positive cells were found in the ganglion cell layer. Therefore, the reduction of the ganglion cell layer should be primarily caused by the observed increase of apoptosis, most likely affecting ganglion cell precursors. Although further work is required for the precise establishment of the ongoing chain of events, we suggest that a critical period in the generation of ganglion cells exists between the last S-phase of the precursors and the migration of the young neuroblasts to the ganglion cell layer. Ras/Raf activation is clearly essential in this period, although we cannot exclude that c-Raf signaling is also essential at earlier or later stages of retinal neurogenesis for additional processes. RCAS integration occurs during an $\mathrm{S}$-phase. This fact, combined with the experimental window (E4.5-E7.5) used, circumscribe our observations to the process of generation of retinal ganglion cells from neuroepithelial precursors. Our preliminary observations on the recovery of the system at longer times suggest that neurogenesis is delayed more than permanently disrupted, a possibility compatible with the phenotype of the knock-out mice (Wojnowski et al., 1998).

The process that gives rise to a mature retina from a proliferative neuroepithelium is well characterized morphologically $(\mathrm{Fu}-$ jita, 1962; Kahn, 1974; Rager, 1980; Spence and Robson, 1989; Prada et al., 1991). Proliferative cells are easily labeled by incorporation of DNA precursors, and there are several markers for mature neurons. The central event of neurogenesis, which occurs in the period between the "last" S-phase and the expression of early neuronal markers, nonetheless remains primarily uncharacterized. In parallel, the molecular basis of the decision to leave the cell cycle and differentiate or to continue proliferating remains obscure. It has been demonstrated recently that this decision is controlled by the Delta-Notch system, especially for early neuronal phenotypes, such as the retinal ganglion cells (Austin et al., 1995; Dorsky et al., 1995; Henrique et al., 1997). Cells expressing Delta, which maintain proliferation of the surrounding neuroepithelial cells by a lateral inhibition mechanism, appear to be those leaving the cell cycle to become ganglion cell neuroblasts (Henrique et al., 1997). Our observations outline the same intermediate cellular stage, generating ganglion cells, as a critical decision point at which c-Raf signaling is essential. Another molecule probably involved in this decision process is, surprisingly, the well known molecular chaperone Hsc70. Early neuroepithelial cells express Hsc70, which disappears from the cells that continue to proliferate and is retained by the ganglion cells (Hernández-Sánchez et al., 1994; Morales et al., 1998). The postulated correlation between the decision to leave the cell cycle or not and the incidence of apoptosis may be the consequence of a signaling conflict leading to apoptosis (Raff, 1992; Raff et al., 1993). At this decision point, the cells may receive the signals upregulating Delta and inducing differentiation in confrontation with the Delta signal itself, which inhibits differentiation. Supporting this hypothesis, Blaschke et al. (1998) have found a temporal and spatial correlation of apoptosis with initial neuronal differentiation all over the neuroepithelium. In parallel with the classical neurotrophic theory, which clearly establishes the role of programmed cell death in the adjustment of the numbers of connecting neurons with target cells (Barde, 1989; Oppenheim, 1989, 1991), the "last cycle" (period between the last S-phase and the expression of specific differentiation markers) may be an appropriate period to regulate the size of generating neuronal populations.

The approach reported here combining in vivo signaling pathway interference with a detailed analysis of the affected developmental processes helps to define specific roles in neural development for pleiotropic signaling molecules, in particular the requirement of Raf for survival in a critical transition point between proliferation and differentiation during neurogenesis.

\section{REFERENCES}

Alexiades MR, Cepko CL (1997) Subsets of retinal progenitor display temporally regulated and distinct biases in the fates of their progeny. Development 124:1119-1131.

Altshuler DM, Turner DL, Cepko C (1991) Specification of cell type in the vertebrate retina. In: Development of the visual system (Lau DM, Shatz CJ, eds), pp 37-58. Cambridge, MA: MIT.

Austin CP, Feldman DE, Ida JA, Cepko C (1995) Vertebrate retinal ganglion cells are selected from competent progenitors by action of Notch. Development 121:3637-3650.

Barde Y-A (1989) Trophic factors and neuronal survival. Neuron 2:1525-1534.

Blaschke AJ, Staley K, Chun J (1996) Widespread programmed cell death in proliferative and postmitotic regions of the fetal cortex. Development 122:1165-1174.

Blaschke AJ, Weiner JA, Chun J (1998) Programmed cell death is a universal feature of embryonic and postnatal neuroproliferative regions throughout the central nervous system. J Comp Neurol 396:39-50.

Bruder JT, Heidecker G, Rapp UR (1992) Serum-, TPA- and Rasinduced expression from Ap-1/ets-driven promoters requires Raf-1 kinase. Genes Dev 6:545-556.

Calogeraki I, Barnier JV, Eychène A, Felder M-P, Calothy G, Marx M (1993) Genomic organization and nucleotide sequence of the coding region of the chicken c-Rmil(B-Raf-1) proto-oncogene. Biochem Biophys Res Commun 193:1324-1330.

Cameron HA, Hazel TG, McKay DG (1998) Regulation of neurogenesis by growth factors and neurotransmitters. J Neurobiol 36:287-306.

Cepko CL, Austin CP, Yang X, Alexiades M, Ezzeddine D (1996) Cell fate determination in the vertebrate retina. Proc Natl Acad Sci USA 93:589-595.

Cepko C, Ryder E, Austin C, Golden J, Fields-Berry S (1998) Linage analysis using retroviral vectors. In: Cellular and molecular procedures in developmental biology (De Pablo F, Ferrús A, Stern CD, eds), pp 51-74. San Diego: Academic.

Chao MV (1992) Growth factor signaling: where is the specificity? Cell 68:995-997.

Cook B, Portera-Cailliau C, Adler R (1998) Developmental neuronal death is not a universal phenomenon among cell types in the chick embryo retina. J Comp Neurol 396:12-19.

Cuadros MA, Ríos A (1988) Spatial and temporal correlation between early nerve fiber growth and neuroepithelial cell death in the chick embryo retina. Anat Embryol 178:543-551.

Daum G, Eisenman-Tappe I, Fries HW, Troppmair J, Rapp UR (1994) The ins and outs of Raf kinases. Trends Biochem Sci 19:474-480.

de la Rosa EJ, Kayyem JF, Roman JM, Stierhof YD, Dreyer WJ, Schwarz U (1990) Topologically restricted appearance in the developing chick retinotectal system of Bravo, a neural surface protein: experimental modulation by environmental cues. J Cell Biol 111:3087-3096.

de la Rosa EJ, Arribas A, Frade JM, Rodríguez-Tébar A (1994) Role of neurotrophins in the control of neural development: neurotrophin-3 promotes both neuron differentiation and survival of cultured chick retinal cells. Neuroscience 58:347-352.

de la Rosa EJ, Díaz B, De Pablo F (1998) Organotypic culture of the chick embryonic retina. In: Cellular and molecular procedures in developmental biology (De Pablo F, Ferrús A, Stern CD, eds), pp 133144. San Diego: Academic.

De Pablo F, de la Rosa EJ (1995) The developing CNS: a scenario for the action of proinsulin, insulin and insulin-like growth factors. Trends Neurosci 18:143-150.

Díaz B, Pimentel B, De Pablo F, de la Rosa EJ (1999) Apoptotic cell death of proliferating neuroepithelial cells in the embryonic retina is prevented by insulin. Eur J Neurosci 11:1624-1632.

Díaz B, Serna, J, De Pablo F, de la Rosa EJ (2000) In vivo regulation of 
cell death by embryonic (pro)insulin and the insulin receptor during early retinal neurogenesis. Development, in press.

Dickson B, Sprenger F, Morrison D, Hafen E (1992) Raf functions downstream of Ras-1 in the sevenless signal transduction pathway. Nature 360:600-603.

Dorsky IR, Rapaport DH, Harris WA (1995) Notch inhibits cell differentiation on the Xenopus retina. Neuron 14:487-496.

Fekete MD, Pérez-Miguelsanz J, Ryder FE, Cepko C (1994) Clonal analysis in the chicken retina reveals tangential dispersion of clonally related cells. Dev Biol 166:666-682.

Ferrell Jr JE (1996) MAP kinases in mitogenesis and development. Curr Top Dev Biol 33:1-60.

Frade JM, Rodríguez-Tébar A, Barde Y-A (1996) Induction of cell death by endogenous nerve growth factor through its p75 receptor. Nature 383:166-168.

Frade JM, Bovolenta P, Martínez-Morales JR, Arribas A, Barbas JA, Rodríguez-Tébar A (1997) Control of early cell death by BDNF in the chick retina. Development 124:3313-3320.

Fujita S (1962) Kinetics of cellular proliferation. Exp Cell Res 28:52-60.

Han M, Golden A, Han Y, Sternberg PW (1993) C. elegans lin-45 raf gene participates in let-60 ras-stimulated vulval differentiation. Nature 363:133-140.

Harris W (1997) Cellular diversification in the vertebrate retina. Curr Opin Gen Dev 7:651-658.

Heidecker G, Huleihel M, Cleveland JL, Kolch W, Beck TW, Lloyd P, Pawson T, Rapp UR (1990) Mutational activation of c-raf-1 and definition of the minimal transforming sequence. Mol Cell Biol 10:2503-2512.

Henrique D, Hirsinger E, Adam J, Le Roux I, Pourquié O, Ish-Horowicz D, Lewis J (1997) Maintenance of neuroepithelial progenitor cells by Delta-Notch signaling in the embryonic chick retina. Curr Biol 7:661-670.

Hernández-Sánchez C, Frade JM, de la Rosa EJ (1994) Heterogeneity among neuroepithelial cells in the chick retina revealed by immunostaining with monoclonal antibody PM1. Eur J Neurosci 6:105-114.

Hernández-Sánchez C, López-Carranza A, Alarcón C, de la Rosa EJ, De Pablo F (1995) Autocrine/paracrine role of insulin-related growth factors in neurogenesis: local expression and effects on cell proliferation and differentiation in retina. Proc Natl Acad Sci USA 92:9834-9838.

Holt CE, Bertsch TW, Ellis HM, Harris WA (1988) Cellular determination in the Xenopus retina is independent of lineage and birth date. Neuron 1:15-26.

Hughes SH, Greenhouse JJ, Petropoulos CJ, Sutrave P (1987) Adaptor plasmids simplify the insertion of foreing DNA into helperindependent retroviral vectors. J Virol 61:3004-3012.

Jansen HW, Bister K (1985) Nucleotide sequence analysis of the chicken gene c-mil, the progenitor of the retroviral oncogene v-mil. Virology $143: 359-367$

Kahn AJ (1974) An autoradiographic analysis of the time of appearance of neurons in the developing chick neuronal retina. Dev Biol 38:30-40.

Lillien L (1998) Neural progenitors and stem cells: mechanisms of progenitor heterogeneity. Curr Opin Neurobiol 8:37-44.

Magnuson N, Beek T, Vahidi H, Hahn H, Smola U, Rapp UR (1994) The Raf-1 serine/threonine protein kinase. Semin Cancer Biol 5:247-253

Marshall JC (1994) MAP kinase kinase kinase, MAP kinase kinase and MAP kinase. Curr Opin Gen Dev 4:82-89.

Martín-Partido G, Rodríguez-Gallardo L, Alvarez IS, Navascués J (1988) Cell death in ventral region of the neural retina during early development of the chick embryo eye. Anat Rec 222:272-281.

Marx M, Crisanti P, Eychène A, Béchade C, Laugier D, Ghysdaël J, Pessac B, Calothy G (1988a) Activation and transduction of c-mil sequences in chicken neuroretina cells induced to proliferate by infection with avian lymphomatosis virus. J Virol 62:4627-4633.

Marx M, Eychène A, Laugier D, Béchade C, Crisanti P, Dezélée P, Pessac B, Calothy G (1988b) A novel oncogene related to c-mil is transduced in chicken neuroretina cells induced to proliferate by infection with an avian lymphomatosis virus. EMBO J 11:3369-3373.

McLoon SC, Barnes RB (1989) Early differentiation of retinal ganglion cells: an axonal protein expressed by premigratory and migrating retinal ganglion cells. J Neurosci 9:1424-1432.

Morales AV, Serna J, Alarcón C, de la Rosa EJ, De Pablo F (1997) Role of prepancreatic (pro)insulin and the insulin receptor in prevention of embryonic apoptosis. Endocrinology 138:3967-3975.

Morales AV, Hadjiargyrou M, Díaz B, Hernández-Sánchez C, De Pablo F, de la Rosa EJ (1998) Heat shock proteins in retinal neurogenesis: identification of the PM1 antigen as the chick Hsc70 and its expression in comparison to that of other chaperones. Eur J Neurosci 10:3237-3245.

Morgan BA, Izpisúa-Belmonte JC, Duboule D, Tabin CJ (1992) Targeted misexpression of Hox-4,6 in the avian limb bud causes apparent homeotic transformations. Nature 358:236-240.

O'Brien RM, Granner DK (1996) Regulation of gene expression by insulin. Physiol Rev 76:1109-1161.

Oppenheim RW (1989) The neurotrophic theory and naturally occurring motoneuron death. Trends Neurosci 12:252-255.

Oppenheim RW (1991) Cell death during development of the nervous system. Annu Rev Neurosci 14:453-501.

Owaki H, Varma R, Gillis B, Bruder JT, Rapp UR, Davis LS, Geppert TD (1993) Raf-1 is required for T cell IL2 production. EMBO J 12:4367-4373.

Prada C, Puga J, Pérez-Méndez L, López R, Ramírez G (1991) Spatial and temporal patterns of neurogenesis in the chick retina. Eur J Neurosci 3:559-569.

Prasad S, Soldatenkov VA, Srinivasarao G, Dritschilo A (1999) Intermediate filament proteins during carcinogenesis and apoptosis. Int $\mathrm{J}$ Oncol 14:563-570.

Pritchard C, McMahon M (1997) Raf revealed in life-or-death decisions. Nat Genet 16:214-215.

Pritchard CA, Bolin L, Slattery R, Murray R, McMahon M (1996) Post-natal lethality and neurological and gastrointestinal defects in mice with targeted disruption of the A-raf protein kinase gene. Curr Biol 6:614-617.

Raff MC (1992) Social controls on cell survival and cell death. Nature 356:397-400.

Raff MC, Barres BA, Burne JF, Coles HS, Ishizaki Y, Jacobson MD (1993) Programmed cell death and the control of cell survival: lessons from the nervous system. Science 262:695-700.

Rager GH (1980) Development of retinotectal projection in the chicken. Adv Anat Embryol Cell Biol 63:I-VIII.

Reh TA, Levine EM (1998) Multipotential stem cells and progenitors in the vertebrate retina. J Neurobiol 36:206-220.

Rodríguez-Tébar A, Jeffrey PL, Thoenen H, Barde YA (1989) The survival of chick retinal ganglion cells in response to brain-derived neurotrophic factor depends on their embryonic age. Dev Biol 136:296-303.

Rommel C, Hafen E (1998) Ras: a versatil cellular switch. Curr Opin Gen Dev 8:412-418.

Sanz C, León Y, Troppmair J, Rapp UR, Varela-Nieto I (1999) Strict regulation of c-Raf kinase levels is required for early organogenesis of vertebrate inner ear. Oncogene 18:429-437.

Snow RL, Robson JA (1995) Migration and differentiation of neurons in the retina and optic tectum of the chick. Exp Neurol 134:13-24.

Spence SG, Robson JA (1989) An autoradiographic analysis of neurogenesis in the chick retina in vitro and in vivo. Neuroscience 32:801-812.

Turner DL, Cepko CL (1987) A common progenitor for neurons and glia persists in rat retina late in development. Nature 328:131-136.

Turner DL, Snyder EY, Cepko CL (1990) Lineage-independent determination of cell type in the embryonic mouse retina. Neuron 4:833-845.

Wetts R, Fraser SE (1988) Multipotent precursors can give rise to all major cell types of the frog retina. Science 239:1142-1144.

Wojnowski L, Zimmer MA, Beck WT, Hahn H, Bernal R, Rapp UR, Zimmer A (1997) Endothelial apoptosis in B-Raf deficient mice. Nat Genet 16:293-297.

Wojnowski L, Stancato LF, Zimmer MA, Hahn H, Beck TW, Larner AC, Rapp UR, Zimmer A (1998) c-Raf-1 protein kinase is essential for mouse development. Mech Dev 76:141-149. 